\title{
Survey of psychological disturbance in patients attending a sexually transmitted diseases clinic
}

\author{
R FITZPATRICK, D FROST, AND G IKKOS \\ From the Academic Department of Psychiatry, Middlesex Hospital Medical School, London
}

SUMMARY A survey of psychological disturbance was conducted in a sexually transmitted disease (STD) clinic, using the general health questionnaire, the Crown-Crisp experiential index, and the illness concern questionnaire. Of 381 patients who completed the questionnaire, $158(43 \%)$ had general health questionnaire scores indicating that they were psychiatric cases. Psychological disturbance was more common in women. The association between general health questionnaire caseness and patients' reports of concerns and worries about illness in relation to their presenting complaint was significant. The Crown-Crisp experiential index scores of cases were lower than those characteristic of patients attending psychiatric clinics, and much of the psychological disturbance found by this and other surveys of STD clinics may therefore represent distress in relation to the presenting problem. Of the 381 patients, $14(4 \%)$ appeared to have an abnormal or unwarranted level of distress in relation to their presenting complaint.

\section{Introduction}

Several studies have drawn attention to the appreciable level of psychological disturbance found in patients attending clinics for sexually transmitted disease (STD). ${ }^{12}$ Various approaches have been adopted to explain such findings. One approach has been to investigate the patients referred from clinics to psychiatrists. ${ }^{3}$ Such studies indicate that patients' concerns and fears about STD may play an important part in the development of psychological distress. ${ }^{4}$ As referrals are uncommon, however, it is difficult to draw from them firm conclusions about the reasons for psychological disturbance in general patients attending STD clinics. One alternative is to use psychiatric survey techniques to investigate more representative samples of patients. This paper reports an investigation conducted in 1984 at the STD clinic of this hospital in which we assessed the level of psychiatric morbidity in new clinic attenders and examined concern about illness and other specific psychological traits that might be responsible for such morbidity.

\section{Patients and methods}

Consecutive new patients attending the clinic were asked by a member of staff to complete a

Address for reprints: Dr R Fitzpatrick, Academic Department of Psychiatry, Middlesex Hospital Medical School, London W1 P 8AA

Accepted for publication 21 August 1985 questionnaire while waiting to be seen. The questionnaire was composed of three sections. The first part consisted of the general health questionnaire, which is a widely used and validated instrument that is self administered and aimed at identifying psychiatric cases. ${ }^{5}$ This study used the 30 item version, in which patients scoring five or more are regarded as probable psychiatric cases. The second section consisted of the Crown-Crisp experiential index, which is also a self administered questionnaire and is intended to measure six distinct categories of psychoneurosis. ${ }^{6}$ The categories designate patients as having: anxiety, phobia, obsession, somatic symptoms (that is, showing somatic concomitants of anxiety, such as breathlessness), depression, or hysteria. We constructed the third part, the illness concern questionnaire, for use in investigating different kinds of worry and concern held by patients attending STD clinics in relation to their presenting complaint. In this version of the questionnaire three questions were asked: (1) how concerned are you about the possibility of a serious illness?, (2) how worried are you about the implications of such an illness on your general health, sexual life or fertility?, and (3) how much has worry about the possibility of illness interferred with your daily life? Respondents assessed the degree of their concern using four grades of severity from "not at all" to "very much".

The medical notes of each patient were examined subsequently to obtain the diagnosis. This was then 
classified into the nine diagnostic categories used by Belsey and Adler in their study of STD clinic attenders in England and Wales, ${ }^{7}$ except that two additional categories, syphilis and "no abnormaility detected", were used. Each patient's sexual orientation was also obtained from the medical notes.

\section{Statistical tests}

We estimated the significance of differences between groups by the $\chi{ }^{2}$ test and Student's $t$ test.

\section{Results}

Of the 381 patients who completed the questionnaires, most $(208(54.6 \%))$ were women and most $(284$ $(74.5 \%)$ ) were single. The mean age of the men was 28.4 and of the women 25.6 years. They were predominantly middle class; in terms of the Registrar General's classification, $274(72 \%)$ were coded as social class I, II or III non-manual. The level of education was high; $259(68 \%)$ held A level general certificates of education or more advanced qualifications.

Patients who scored five or more with the general health questionnaire ("cases") numbered $164(43 \%)$; $198(52 \%)$ were women compared with $122(32 \%)$ men

TABLEI Diagnoses of 370 patients and proportion of them who were psychiatric cases according to the general health questionnaire

\begin{tabular}{|c|c|c|}
\hline Diagnosis & $N o(7)$ & $\begin{array}{l}\text { No(\%) who were } \\
\text { ps!chiatric cases }\end{array}$ \\
\hline Gonorrhoea & $10 \quad(2 \cdot 7)$ & $2(20 \cdot 0)$ \\
\hline Syphilis & $2(0.5)$ & $1(50 \cdot 0)$ \\
\hline Trichomoniasis & $11 \quad(3 \cdot 0)$ & $6(54.5)$ \\
\hline Candidosis & $41(11 \cdot 1)$ & $19(46 \cdot 3)$ \\
\hline Genital herpes & $21 \quad(5 \cdot 7)$ & $8(38 \cdot 1)$ \\
\hline Genital warts & $31 \quad(8.4)$ & $14(45 \cdot 2)$ \\
\hline Non-specific infection & $92(24.9)$ & $34(37 \cdot 0)$ \\
\hline $\begin{array}{l}\text { Other conditions } \\
\text { requiring treatment }\end{array}$ & $22 \quad(5 \cdot 9)$ & $12(54 \cdot 5)$ \\
\hline $\begin{array}{l}\text { Other conditions not } \\
\text { requiring treatment }\end{array}$ & $89(24 \cdot 1)$ & $46(51 \cdot 7)$ \\
\hline Other & $9(2 \cdot 4)$ & $3(33 \cdot 3)$ \\
\hline No abnormality detected & $42(11 \cdot 4)$ & $13(31 \cdot 0)$ \\
\hline Total & $370(100 \cdot 0)$ & $158(43 \cdot 0)$ \\
\hline
\end{tabular}

TABLE II Mean scores of 381 patients by the Crown-Crisp experiential inde.

\begin{tabular}{lll}
$\begin{array}{l}\text { Diagnostic } \\
\text { category }\end{array}$ & Mean scores in men & Mean scores in women \\
\hline Anxiety & $4 \cdot 7$ & $6 \cdot 5$ \\
Phobica & $3 \cdot 7$ & $4 \cdot 2$ \\
Obsession & $6 \cdot 1$ & $6 \cdot 6$ \\
Somatic symptoms & $3 \cdot 9$ & $4 \cdot 8$ \\
Depression & $4 \cdot 1$ & 4.4 \\
Hysteria & $6 \cdot 1$ & 6.8 \\
\hline
\end{tabular}

$\left(\chi^{2}=15.865 ; \mathrm{p}<0.0001\right)$. The caseness did not appreciably relate to age, education, or social class. Table I shows the proportion of potential cases in the different diagnostic categories. The highest proportion of cases occurred in patients with trichomoniasis and those with symptoms but no STD ("other conditions requiring treatment" and "other conditions not requiring treatment"). One of the lowest rates of psychiatric caseness was in patients who had no detectable illness.

In terms of sexual orientation, the proportion of cases was higher in heterosexuals than homosexuals $\left(\chi^{2}=7.309 ; \mathrm{p}<0.01\right)$. The diagnostic category "no abnormality detected" was more common in homosexual patients. When patients in this diagnostic category were excluded from analysis, caseness was still more common in heterosexuals $(175(46 \%))$ than homosexuals $(118(31 \%))$ but the difference was no longer significant. The difference between the number of cases in homosexual compared with heterosexual men was also not significant.

The pattern of higher scores in women than men was also found from the Crisp-Crown experiential index (table II). The mean scores of women were higher in all categories, and the differences between men and women were significant in those who were anxious ( $<00.001)$, had somatic symptoms $(p<0.01)$ or were hysterical $(p<0.05)$. Age was not related to score. The scores in all categories of the Crown-Crisp experiential index were lower for homosexual than for heterosexual patients. Attenders with a lower educational level or social class had significantly higher scores for phobia $(p<0.001)$, but for no other category.

The scores obtained from our patients were compared with those obtained from both psychiatric outpatients ${ }^{8}$ and from the general population'. Using the six categories of the Crown-Crisp experiential index, table III compares the mean scores of the following group of patients: (1) 205 attenders at the STD clinic with general health questionnaire scores of four or less, which identified them as psychiatrically well; (2) 158 attenders at the STD clinic with general health questionnaire scores of five or more, which identified them as potential cases, (3) 126 members of the general public aged 25 to 34 ; and (4) 780 patients referred to psychiatric outpatient clinics.

Table III shows that patients attending the STD clinic who were psychologically well according to the general health questionnaire score also had CrownCrisp experiential index scores very similar to those of the general population. Indeed, in five out of six categories women's scores were lower than those of the general population. Patients attending the clinic who were cases according to their general health questionnaire scores had considerably lower scores than those characteristic of psychiatric patients. The 
TABLE III Mean Crown-Crisp experiential index scores of STD clinic attenders (well and psychiatric cases) and comparison samples (members of the general population and psychiatric patients)

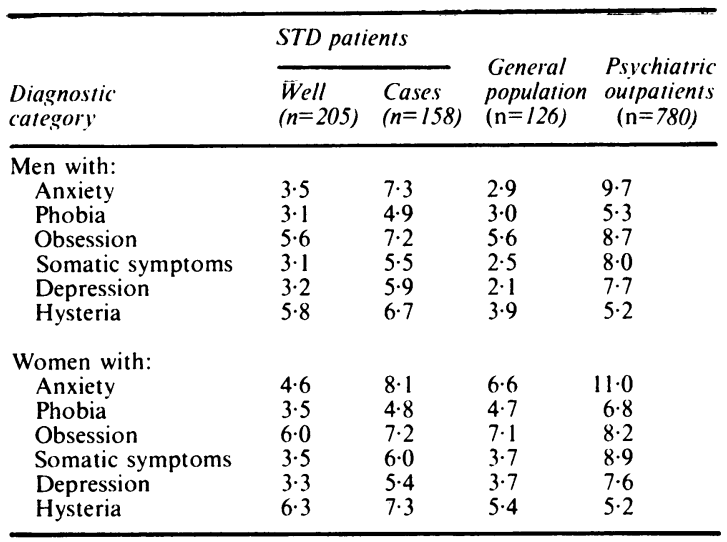

exceptions were that scores in men with phobia were the same as those found in psychiatric patients and, secondly, that men and women STD patients, whether psychologically well or cases, had particularly high scores for hysteria compared with the other populations.

Table IV shows the results of the illness concern questionnaire. Of the 381 STD clinic attenders, 255 (59\%) expressed themselves as being moderately or very concerned about the possibility of serious disease and more $(278(73 \%))$ were concerned with the social implications for their lives that illness might have. Though most patients expressed such concerns, 156 $(41 \%)$ said that such worries and concerns had moderately or very much interferred with their daily lives. Demographic variables were not related to illness concern except that patients with less education expressed higher levels of concern about serious disease $\left(\chi^{2}=30 \cdot 146 ; p<0 \cdot 01\right)$ and experienced more disruption of daily life caused by concern than better educated patients $\left(\chi^{2}=24.7 ; p<0 \cdot 05\right)$. Married patients also experienced more disruption to daily life because of concern than single patients $\left(\chi^{2}=11 \cdot 304 ; p\right.$ $<0.01$ ). More patients with symptoms but no sexually transmitted disease (those with "other conditions requiring treatment" and "other conditions not requiring treatment") expressed concern about the possibility of a serious disease and about the social implications of illness $(p<0.05)$.

Caseness (as shown by the general health questionnaire) was significantly related to all three dimensions of concern about illness - concern about serious disease $\left(\chi^{2}=17.733 ; p<0.001\right)$, concern about the social implications of illness $\left(\chi^{2}=24.999 ; p<\right.$ $0.001)$, and concern that disrupted daily life $\left(\chi^{2}=32.976 ; p<0.001\right)$.

\section{Discussion}

The finding of a $43 \%$ rate of psychiatric caseness might be regarded as suprisingly high. Pedder and Goldberg's study of patients attending the same clinic using the same instrument, the general health questionnaire, found $30 \%$ of new attenders to be psychiatric cases. ${ }^{2}$ Part of the differences between the two surveys can be accounted for by the higher ratio of women, who are more often psychiatric cases, in the study published here. The pattern of diagnoses in the two surveys was also different. The percentage of patients diagnosed as having gonorrhoea and nonspecific infection was $48 \%$ in Pedder and Goldberg's survey but only $28 \%$ in the report published here. In both studies these categories of disease were associated with scores in the general health questionnaire. Though the differences in sex ratio and in distribution of diagnoses possibly explain the higher scores found in our survey, the casenesses score was still higher in women and in patients with non-specific or gonorrhoea in our study. Another possible explanation for differences in the levels of casenesses between the two studies may be that our patients all completed the questionnaire before seeing the doctor, whereas in the earlier study patients were handed the form to complete after the initial interview with the doctor, when some distress may well have diminished.

Pedder and Goldberg found lower levels of caseness in homosexual compared with heterosexual clinic attenders. Our results from both the general health questionnaire and the Crown-Crisp experiential index support their findings. The lower rate of caseness in homosexuals may partly be interpreted by the finding that they were more often categorised in the clinic as

TABLE IV Distribution of responses by 381 STD clinic attenders to illness concern questionnaire.

\begin{tabular}{|c|c|c|c|}
\hline \multirow[b]{2}{*}{$\begin{array}{l}\text { Level of } \\
\text { concern }\end{array}$} & \multicolumn{2}{|c|}{ No(\%) expressing concern about: } & \multirow[b]{2}{*}{$\begin{array}{l}\text { No('i) with. and extent of, distuption of } \\
\text { daily life catused by concern }\end{array}$} \\
\hline & Possibility of serious discase & Social implications & \\
\hline $\begin{array}{l}\text { None } \\
\text { Little } \\
\text { Moderate } \\
\text { Considerable }\end{array}$ & $\begin{array}{r}63(16.4) \\
93(24 \cdot 4) \\
93(24.4) \\
132(34 \cdot 7)\end{array}$ & $\begin{array}{r}27(7 \cdot 2) \\
76(20 \cdot 0) \\
94(24 \cdot 7) \\
184(48 \cdot 3)\end{array}$ & $\begin{array}{l}106(27 \cdot 7) \\
120(31 \cdot 5) \\
90(23 \cdot 7) \\
65(17 \cdot 1)\end{array}$ \\
\hline
\end{tabular}


having "no abnormality detected", which suggested that they had other reasons for attendance, such as to have a check up. In patients with STD, however, the rate of caseness among homosexuals was also lower, which suggested that emotional disturbance was not characteristic of this group of attenders. Comparison, in male attenders only, of the two sexual orientations supports this view.

Our level of caseness was closer to that found in the STD clinic in. Oxford by Catalan et al, who reported $40 \%$ caseness with the general health questionnaire. ${ }^{10}$ Such high levels of psychological disturbance are quite consistent with results obtained in medical, surgical, and gynaecological patients. ${ }^{11} 12$ The association of psychological disturbance with STD, however, still requires explanation. Catalan et al examined the part that sexual dysfuction might play in psychological disturbance in patients attending STD clinics, but only found an association between sexual dysfunction and caseness in women. Another possible explanation for such psychological disturbance is that it arises from worries related to the presenting symptom. Previous discussion of this aspect of patients attending STD clinics has often been limited to inferences drawn from the few referred to psychiatrists. ${ }^{4}$ Our study examined the distribution of illness concern in unselected attenders. The results of the illness concern questionnaire indicated that most patients felt some appreciable level of concern about the symptoms with which they presented at the clinic. More (73\%) were concerned about the implications of their symptoms for such areas of life as sexual activity than expressed concern simply in terms of fear about a serious disease $(59 \%)$.

The association between general health questionnaire scores and patients' assessments of their concern about illness was consistent with the view that much of the psychological disturbance commonly reported in STD clinics arises from distress felt in relation to the presenting problem. According to this interpretation, many of the cases found in this and other surveys may represent transient distress rather than illnesses of the kind commonly seen in psychiatric clinics. Supporting evidence for this view comes from looking at how general health questionnaire cases scored in six different categories of psychoneurotic illness identified by the Crown-Crisp experiential index. In five of the six categories the scores of general health questionnaire cases were midway between those of psychiatrically well people in the community and those typical of psychiatric patients. The one exception to this was in the category of hysteria, in which clinic attenders who were cases had much higher scores than psychiatric patients. It is interesting that this category may be more a measure of extraversion or "sociability" than of psychiatric symptoms of hysteria. ${ }^{9}$
Not all patients respond to illness to the same extent. Those who are chronically anxious or who habitually worry about their bodily health will possibly respond with increased anxiety to symptoms of physical illness. A new way of scoring the general health questionnaire has recently been proposed, which might help to identify such chronic anxiety. ${ }^{13}$ Another instrument, the illness behaviour questionnaire ${ }^{14}$ is available with which this possibility may be examined. In our study these methods were used to examine further the nature of illness concern.

Though concern about the implications of symptoms may well have given rise to many of the high general health questionnaire scores, this does not account for the higher scores in women patients who did not express more concern about illness in either of the ways assessed by our illness concern questionnaire. Higher general health questionnaire scores in women compared with men have been found in other medical settings, ${ }^{15}$ and may reflect the higher level of psychiatric morbidity found in women in random community samples. It has also been suggested, however, that such differences arise from the "expressiveness" of women - their greater readiness to express or report symptoms compared with men. ${ }^{16}$ This may be the interpretation of our finding that, though having the same concern about the possible implications of STD as men, they reported more associated distress and disturbance of feelings.

Lastly we can address the issue that has often been discussed - "venereophobia" 17 or more specific fears, such as "syphilophobia". ${ }^{18}$ Such terms refer to abnormal or inappropriate concern about disease. One group in whom such inappropriate fears about STD are most apparent are patients attending STD clinics who prove to have no demonstrable disease. Clinical reports of hypochondriasis have been described in patients referred from STD clinics to psychiatrists. ${ }^{4}$ Our patients provided a way of estimating the incidence of such "venereophobic" concern in the non-referred majority of patients. Fourteen of our patients were found to have no detectable disease but a very high level of concern about their presenting problem. These patients $(4 \%$ of the clinic attenders) may be regarded as having, in principle, an unwarranted degree of concern about STD. They most resemble patients seen by psychiatrists for their abnormal perception of illness.

Patients with symptoms but no definite STD generally expressed concern about their presenting problem. Just as in Pedder and Goldberg's survey, the level of caseness in this group was higher than but not significantly different from that in the rest of the patients. Bridges and Goldberg provided a cautious note about such patients that "...psychiatric illness should not be diagnosed by exclusion of physical disorders, and referral to a psychiatrist should not be 
made just because an organic disease has not been established. ${ }^{13}$

There is some evidence that fear of particularly life threatening diseases, such as the acquired immune deficiency syndrome, is having an impact on sexual behaviour and the consequent pattern of STD in patients at risk. ${ }^{19}$ One main conclusion of our study was that a wide variety of concern and worry about illness was typical of patients attending STD clinics. Such concern may contribute considerably to the levels of distress found in clinics and may be much more important than the atypical syndromes, such as "venereophobia", which were emphasised by earlier psychiatric investigations. Attention needs to be given to the course of concern and its influence on the outcome of medical care.

We thank Dr J S Bingham, Professor M W Adler, and the staff of James Pringle House, Middlesex Hospital, for their help and co-operation in this study.

\section{References}

1. Mayou R. Psychological morbidity in a clinic for sexually transmitted disease. British Journal of Venereal Diseases 1975;51:57-60.

2. Pedder JR, Goldberg DP. A survey by questionnaire of psychiatric disturbance in patients attending a veneral diseases clinic. British Journal of Venereal Diseases 1970;46:58-61.
3 Frost D. Recognition of hypochondriasis in a clinic for sexually transmitted disease. British Journal of Venereal Diseases 1985;61:133-7.

4. Bhanji S, Mahony JDH. The value of a psychiatric service within the venereal disease clinic. British Journal of Venereal Diseases 1978;54:266-8.

5. Goldberg DP. The detection of psychiatric illness by questionnaire. London: Oxford University Press, 1972.

6. Crown S, Crisp AH. A short clinical diagnostic self rating scale for psychoneurotic patients: the Middlesex Hospital questionnaire. Br J Psychiatry 1966;112:917-23.

7. Belsey EM, Adler MW. Study of STD clinic attenders in England and Wales, 1978. 2. Patterns of diagnosis. British Journal of Venereal Diseases 1981;57:290-4.

8. Crown S, Crisp A. Manual of the Crown-Crisp experiential index. London: Hodder and Stoughton, 1979.

9. Crisp AH, Ralph PC, McGuiness B, Harris G. Psychoneurotic profiles in the the adult population. Br $J$ Med Psychol 1978;51:293-301.

10. Catalan J, Bradley M, Gallwey J, Hawton K. Sexual dysfunction and psychiatric morbidity in patients attending a clinic for sexually transmitted diseases. $\mathrm{Br} J$ Psychiatry 1981;138:292-6.

11. Byrne P. Psychiatric morbidity in a gynaecology clinic: an epidemiological survey. Br J Psychiatry 1984;144:28.34.

12. Nabarro J. Unrecognised psychiatric illness in medical patients. Br Med J 1975;289:635-6.

13. Goodchild $\mathbf{M}$, Duncan-Jones $\mathbf{P}$. Chronicity and the general health questionnaire. Br J Psychiatry 1985;146:55-61.

14. Pilowski I, Spence N. Patterns of illness behaviour in patients with intractable pain. J Psychosom Res 1975;19:279-86.

15. Bridges $\mathrm{KW}$, Goldberg DP. Psychiatric illness in inpatients with neurological disorders. $B r$ Med J 1984;289:656-8.

16. Briscoe M. Sex differences in perceptions of illness and expressed life satisfaction. Psychol Med 1978;8:339-45.

17. Kite E, Grimble A. Psychiatric aspects of venereal disease. British Journal of Venereal Diseases 1963;39:173-80.

18. MacAlpine I. Syphilophobia. British Journal of Venereal Diseases 1957;33:92-9.

19. Weller IV, Hindley DJ, Adler MW, Meldram JT Gonorrhoea in homosexual men and media coverage of the acquired immune deficiency syndrome in London, 1982-3. Br Med $J$ 1984;289:1041. 